\title{
A Process-Oriented Model to Business Value - the Case of Real-Time IT Infrastructures
}

\author{
Carina Cundius \\ Leipzig University, Germany \\ carina.cundius@uni-leipzig.de
}

\author{
Rainer Alt \\ Leipzig University, Germany \\ rainer.alt@uni-leipzig.de
}

\begin{abstract}
Which investments in real-time capabilities and decision-support IT-infrastructures are appropriate? In view of the recent in-memory systems this poses an urgent question to companies in many industries. Despite ample research on the causal relationship between IS investments and business value, especially the value quantification remains a difficult challenge. This paper contributes a business value measurement model that structures and assesses the internal organizational benefits of real-time IT infrastructures. A case study from the automotive industry aims to validate the model.
\end{abstract}

\section{Introduction}

Competing on time has gained importance for many manufacturing companies. A quick response has become a key success factor in case of critical events, in order to minimize costs and maintain product excellence. For example, a global automobile group requires production and logistics processes with (near) real-time information capability and the ability to sustain fast decisions due to a just-in sequence (JIS) production environment. The delivery of internal manufactured components (engines, axles) needs to be aligned to the demands of the production line. Disruption-related delays, require a rescheduling of the component production and affect their delivery time. Thus, to react fast and flexible, planners require status information about the production line every 10 15minutes. Otherwise, costly line stoppages are possible. Furthermore, the time to react on vehicle errors may be reduced: Immediately after detecting a constructional or functional fault, the quality audit reports this error and has the ability to initiate countermeasures. This is important since every defective item causes additional rework, which in turn leads to increased expenses. Delays in information transfer and fault detection may generate warranty claims and affect customer satisfaction. As this example illustrates, decision-makers highly benefit from timely data to analyze, control and manage their operational production processes.

Other industries, such as energy producers share similar problems and benefit from real-time information in the same way. The idea of real-time business has been discussed since more than twenty years. Contrary to the definition of computer science, 'real-time' in the IS discipline is associated with the objective of dialogue processing and interactive networking. Real-time technologies support the availability, accessing and processing of (near) realtime information and enable faster response times [1]. These concepts have gained new momentum due to technological advances in the field of databases, data storage, etc. Current data management platforms that respond in real-time may be realized by inmemory data management (IMDM) solutions. Successful application scenarios of IMDM do exist and already have been described by academia [2, 3]. But, systematic business value evaluations are still an open field for research. This applies to other (near) real-time IT infrastructures too, such as operational Business Intelligence (opBI) technologies that intend to realize decision-making on transactional data.

With the advent of real-time technologies for practical application, the question remains, if the promises of instant information are met. How do speed advantages actually affect an organization? "Business IT alignment" is considered essential in order to control the IT value contribution and is seen as a driver of firm performance [4]. Thus, companies are faced with the question whether and which investments in real-time capabilities are reasonable? So far, it lacks reliable studies and especially, models for economic analyses. Hence, further refinement and extensions of previous approaches are required.

This work intents to contribute a conceptual model for determining the value of investments in real-time IT infrastructures. Applied from companies (e.g. IT executives), the model purposes to shed light on the suitability of implementing such a technology. Predominantly, this paper derives and validates 
suitable measurement value items for assessing the internal organizational benefits. The investigation is based on cases of (near) real time processing from an integrated case study from the automotive industry. The findings are embedded into a business value model, which is an adaption of a number of wellknown models for IT value and IS success. Following existing process-oriented frameworks, the paper argues that the additional value for the business is essential. Thus, first-order effects arise on business process (BP) level. Further, the monetarization of organizational business value, resulting from implementing a (near) real-time infrastructure, is seen as a crucial consideration aspect in order to support a company's IT investment decisions.

\section{Methodology}

On the basis of an extensive literature review [5] and first-hand knowledge from various case studies (Tab. 1), this paper aims to elaborate the business value of (near) real-time IT infrastructures. The research addresses the following research question: How can organizational implications of real-time ITinfrastructures be determined on a conceptual level with regard to support IT investment decisions?

Incipient, based on existing work a conceptual model is developed that structures and assesses the benefits. To determine especially the organizational impact, the definition of suitable value items is crucial. Beside deductive knowledge from prior publications, findings from use cases are strongly applied for deriving these value items. In-depth case studies are seen as appropriate for investigating the multiple interdependencies and complex value networks in the considered research field as well as for developing artefacts for problem solving.

Table 1. Examined (near) real-time use cases

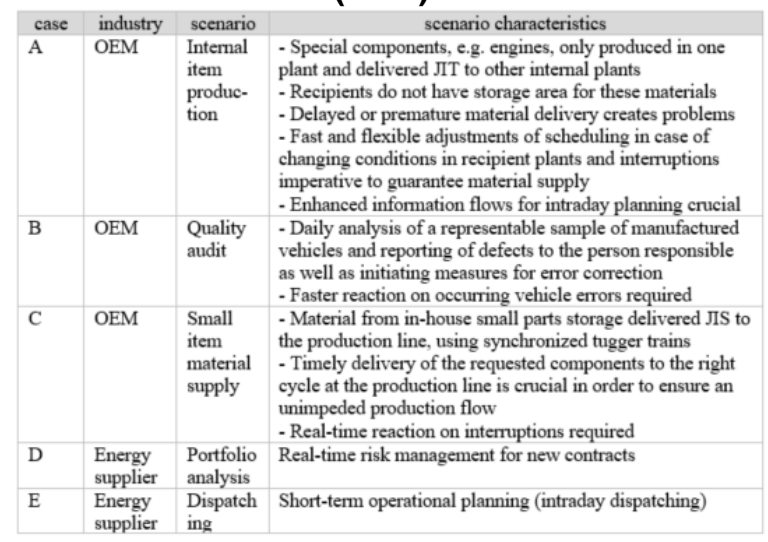

This paper exemplarily reports on a case study nearly completed in one manufacturing plant of a large global automotive company (Tab.1, A-C and mentioned in section 1). Due to the consideration of different departments respectively BPs within the organization, it is about an integrated case study [6]. Different data collection techniques have been used in order to answer the research question: workshops, document and system analysis, observations and interviews - the most important source of case study evidence [6]. The interviews, among others, assist to identify the diverse needs of decision-relevant realtime information for the given scenarios.

Initially, potential BPs for real-time decision support have been discussed in two workshops with the head of the business intelligence (BI) section and the head of IT. A prepared set of criteria for detecting real-time processes supported this assessment. The representatives have been chosen, because all kind of arising requirements regarding a better IT-support for the company's worldwide production and logistic processes are communicated to them. Second, the identified BPs have been analyzed in detail with the aid of observations, interviews and document analysis. A semistructured interview guide has been used for the individual interviews conducted with two representatives of the particular departments, their area managers and the respective BI counterpart. This guide inquires process operations, points of decision, technical infrastructure, typical process disruptions and latency causes. Further, potential intraday or realtime relevant decision situations have been enquired. In addition, every BP of the particular scenarios has been observed and existing documents containing visualizations, system properties, text descriptions and performance indicators have been examined.

Implying the insights from the in-depth analyses and existing literature about value parameters, several value items and suitable measurement procedures to determine the business value of a real-time IT infrastructure have been derived using the instrument of influence diagrams. The measurement approach is currently being validated. This paper exemplarily reports on two validation scenarios (Tab.1, B and C).

The paper is structured as follows: Section 3 presents existing literature about the IT business value and recognizes further research fields. In section 4 the conceptual model and measurement approach are created and initial validation results are presented. Finally, the findings and are summarized.

\section{Status Quo of real-time IT value}

Implementing a new or improved IS to support business activities usually leads to various effects for a company. Measuring how an organization benefits from an IS or IT infrastructure is crucial to judge IT 
investments for both research and practitioners. Under the heading "business value of IT" this topic has been discussed for many years. The value of IT in various applications has been analyzed by several studies that suggest an ample variety of different general assessment models and research approaches. However, only a few of them have been established that, in turn, have limited suitability for this research. Following, principal approaches are analysed.

\subsection{Generic frameworks}

A large body of existing publications emphasizes the organizational output at firm level as well as an increasing market productivity as a consequence of IT investments, measuring e.g. the 'return on investment (ROI)' [7, 8]. Some authors use the theory of resource-based view, which attributes superior financial performance to organizational resources and capabilities, to examine the association between IT capabilities and competitive advantage [9]. However, the impact on process-organization respectively operational business and management processes including the human resources (decisionmaker) has not been considered. Hence, these models on their own are not suitable to explain the investigated topic comprehensively.

Process-oriented models address this deficit. Many researchers argue that the contribution of IT to profitability and productivity does result from its positive impact on business processes (BP) and involved stakeholders. These impacts influence firm performance at the business unit or enterprise level [10]. [11] highlights the focus on the business level as a central aspect of benefit considerations and " $[\ldots]$ recognize that IT is not necessarily the driver of capabilities, but that business capabilities are the primary driver of value, and getting a better grasp on how we IT-ize these capabilities should be a major thrust." [11, p. 36]. Corresponding studies emphasize the operational effectiveness and efficiency. To analyze how IT impacts on BPs, process improvements are crucial, as enhanced BPs result in an increased business value [12]. Despite recognizing the high relevance of process-oriented approaches from both academics and practitioners few researchers have contributed generalized concepts in the past $[13,14]$. Existing frameworks usually finish after specifying objects of measurement. Advices to gain tangible values are rare. Besides, the issue of real-time IT technology has not been linked with existing conceptual process-oriented approaches.

As a third major research aspect, the perceived value and satisfaction with an IT system or service have been addressed. Corresponding publications investigate users satisfaction, that is subject to system performance, reliability and usability as main aspects of value creation [15]. The IS Success Model [16] as well as the Technology Acceptance Model (TAM) [17] are dominant frameworks that have been applied and validated by several researchers. However, models with pure focus on user satisfaction and usage do not seem appropriate to support investment decisions, because purely analysis of qualitative indicators provides little evidence about the value creation process and is not an acceptable alternative to measure performance directly [13].

Despite this body of existing literature, there is still a need to deepen the understanding about the exact way in which IT resources create business value, especially in interaction with other organizational resources such as processes and people [18]. Further, to assess the mentioned benefits of real-time IT infrastructures, merely fragmentary findings exist as the following sections shows.

\subsection{Value of specific technologies}

Besides evaluations of the value of IT in general, researchers strive to better understand the value of specific technologies of their age, e.g. of Enterprise Systems in the 2000s [19]. Considering the current interest in IMDM and other recent real-time IT components (SSD storage, Hadoop framework etc.), there is a clear case for analyzing its business value similar to established approaches. The use of realtime IT infrastructures in order to accelerate decisionsupport has already been addressed in literature.

3.2.1. Operational Business Intelligence. An example is the extension of classical BI to support decision-making on an operational level during the process flow, recently referred to as OpBI or realtime BI $[20,21]$. In the respective OpBI scenarios, the DWH-based systems are used for data integration, data storage, data aggregation and report generation [22]. A large literature review regarding the topic has shown a focus on data-centric or technology-centric issues. Organizational or decisioncentric aspects have been addressed merely from a handful authors. Most of them investigate potential application areas [23] or evidence benefits and advantages or limitations of the concept using exemplary implementations [24]. Theoretical considerations are rare. [25] contributes to the field of real-time BI by extending the practitioner models' latency components in due consideration of decisionmaking theories. [26] discusses a theoretical integration of BI and BP management to support knowledge intensive processes. Additionally, some 
articles are dealing with related topics such as (realtime) BP intelligence [27]. However, it lacks conceptual models about system benefits.

3.2.2. IMDM. The link between operational and analytical IS is enabled by emergent technologies as IMDM. Due to loading and processing all data in the main memory of a system, IMDM accelerates data loading and helps to reduce response times on the database and application layer. As a result of the faster access on data, significant gains in performance are achieved [28]. Meanwhile numerous vendors offer IMDM solutions - one reason for the growing attention. Further, an increasing amount of organizations are faced with the question how to deal with the "Big Data" challenge and IMDM is seen as one method of solution. Research on IMDM and realtime (operating) systems is primarily focused on technical issues of data processing and architectural changes, such as storage and writing algorithms [29]. In parallel, academic literature on the use of IMDM for business applications and on evaluating the investments with focus on the organizational context has evolved. Most researchers attempted to derive suitable business scenarios where IMDM is expected to generate value [20,30]. However, the business value and implications to adjust BPs have so far been addressed only by a handful authors. These contributions are based on IMDM implementations in practice, expert interviews [31, 32] or literature reviews [33]. [2] identified special application scenarios of IMDM in a manufacturing company and derived a value creation model with general principles to consider for creating business value through IMDM. A more generic approach is presented by [3], who systematically relate insights about the business value to real application scenarios in five use cases in industrial and service-sector organizations. Regarding the scare knowledge base about the impact on business, IMDM still leaves ample room for examining the intricate relationship between the IT infrastructure and business value.

Summarized, hardly any research contribution has so far tried to derive a general model to measure the value of investments in real-time IT infrastructures. Given the inconclusive literature base, there is a clear need for further investigations. Hence, a conceptual model that captures the benefits is proposed in the next sections.

\section{Business Value Model}

To assess the benefit of specific IT infrastructures an organization's strategic direction is critical. Based on Porters suggestions to differentially focus on operational effectiveness and strategic positioning when characterizing business strategy, [14] define corresponding IT goals. Thus, the aims regarding operational effectiveness are: reduced operational costs, increased speed and productivity and enhanced organizational effectiveness to support flexibility and responsiveness on changing market conditions. Strategic positioning may benefit from extended geographic reach or customer access and changed industry or market pieces. Similarly, [34] defined a taxonomy to operationalize the "IS business value". The author distinguishes internal vs. external value in a first and tangible vs. intangible value in a second dimension each characterized by special value types. "Internal value is achieved when IS contributes to redesigned business processes, better decisionmaking, improved coordination flexibility and productivity." [34, p.151]. It is assumed that internal value has direct impact on external value.

Besides, [34] suggest three key tasks in order to yield a comprehensive and precise understanding of IS business value: (i) the definition of value types; (ii) the identification of value items to measure the value and (iii) development of procedures, which allow the measurement of the items. Accordingly, the conceptual model is designed.

\subsection{Value dimensions}

Following the mentioned approaches and the argument of many researchers that first-order impacts of IT-investments are generated at the BP level, this paper places emphasis on the internal value of realtime IT infrastructures. The value dimension is operationalized through value types, which influence the operational effectiveness. Having the existing frameworks in mind and focusing on the described domain, a synthesized business value model has been designed to structure the benefit dimensions (Fig.1).

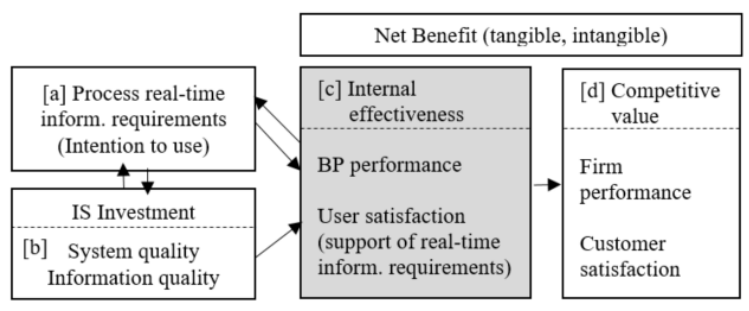

Figure 1: Adapted business value model

The dimensions have been adapted from established models for IT value and IS success. The basic assumption is grounded on the argumentation of process-oriented approaches as well as the resource-based-model of [18] and the taxonomies 
previously mentioned. Besides, some aspects ('system' and 'information quality', 'intention to use', 'Net Benefit') from the IS Success Model [35] have been applied due to its behavioral scientific perspective, general recognition and multiple validations and references. Thus, an interdisciplinary model has been designed that is composed as follows.

Every BP and every decision-maker have specific requirements concerning the timeliness, the frequency and the speed of information for decision support as well as the system response times (SRT). These requirements determine a process' 'real-time level' [36] and trigger the intention to use an appropriate IT infrastructure for decision-support (Fig.1 [a]). Hence, first of all an analysis of a BPs information demand is necessary for recognizing the BPs that have (near) real-time requirements by means of suitable assessment indicators. Such indicators are, for example, the time horizon until analyses results are relevant (organizational latency), the time to action regarding restrictions in process control (decision latency) or the frequency of information changes in BPs [36]. An appropriate IT system has to meet the identified needs of information. Assuming the categories of [35] the IT capabilities are described within the dimensions "information quality" and "system quality" (Fig.1 [b]). Exemplary indicators for assessing the IT system are the time until data is integrated in the data management system (data latency) or SRTs. Adequate quality and usefulness of the information provided for decision-making is presumed. Second, the fit between process requirements and the characteristics of the existing system is to determine. If the real-time information requirements are not satisfied, investments in new real-time capable applications and / or hardware systems become mandatory [36]. Introducing new or adapted IT infrastructures often requires a redesign of existing BPs for achieving significant benefits [37]. As a third step, the business value (Net Benefit) of the (new) system must be assessed (Fig.1 [c, d]) with regard to the (redesigned) BPs that have been identified before. The benefit of dimension [c] mostly appears as a type of cost reduction. An increased competitive value [d] is reflected in revenue growths. According to the emphasis on organizational effects this paper focuses on assessing the value of "internal effectiveness" (Fig.1[c]), which is discussed below.

\subsection{Value items in real-time environments}

To assess the business value, the defined value types of organizational effectiveness ,satisfaction of decision-maker” and „BP performance“ have to be translated into suitable qualitative and quantitative value items as well as methods for measuring them.

Assuming a complex network of various impacts, the value items have to be structured appropriately. Hence, a separation across different organizational BP level seems convenient. According to [37], transactional BPs of the value chain and their associated management processes are distinguished. Additionally, there are analytical BPs that use information, which is accessible to a broad range of recipient, e.g. plant managers or business analysts. Based on a comprehensive study of various types of complex decisions in 26 organisations, [38] introduced a theoretical framework to distinguish different types of relationships between information and decisions. Tab. 2 summarizes the characteristics of the three BP types and their information environments [21, 38].

\section{Table 2. BP types and information needs}

\begin{tabular}{|l|l|l|}
$\begin{array}{l}\text { Business } \\
\text { process type }\end{array}$ & $\begin{array}{l}\text { Information } \\
\text { environment }\end{array}$ & \multicolumn{1}{c|}{ Characteristics } \\
\hline $\begin{array}{l}\text { Transactional } \\
\text { BP }\end{array}$ & $\begin{array}{l}\text { Automated } \\
\text { decision } \\
\text { environment }\end{array}$ & $\begin{array}{l}\text { - well-structured decision-making delegated to } \\
\text { embedded rule-engines } \\
\text { - fully BP automatization by workflow } \\
\text { technologies (BAM) to increase BP efficiency }\end{array}$ \\
\hline $\begin{array}{l}\text { Associated } \\
\text { management } \\
\text { BP }\end{array}$ & $\begin{array}{l}\text { Structured } \\
\text { human-decision }\end{array}$ & $\begin{array}{l}\text { - situational decision-making } \\
\text { - information linked to decision-making process } \\
\text { - focus on particular success-critical decisions }\end{array}$ \\
\hline $\begin{array}{l}\text { Analytical } \\
\text { BP }\end{array}$ & $\begin{array}{l}\text { Loosditional infrastructures to support specific } \\
\text { decision-making }\end{array}$ \\
\hline & $\begin{array}{l}\text { information and } \\
\text { decisions }\end{array}$ & $\begin{array}{l}\text { - typical BI surrounding } \\
\text { - information is intended to inform a wide range } \\
\text { of possible decisions }\end{array}$ \\
\hline & & $\begin{array}{l}\text { - information broadly accessible to analysts and } \\
\text { decision makers }\end{array}$ \\
\hline
\end{tabular}

The paper focuses on accelerating and improving the management BPs, which are associated with transactional BPs in manufacturing companies owing to real-time IT structures. Positive effects, originating from enhanced and faster decision processes for transactional BPs, are assumed. Closely linked to the decision-process is the decision-maker - in addition a critical success factor, which has to be considered.

Using this classification, the value items are differentiated according to BP types. In order to illustrate the multi-level impacts, influence diagrams - a simulation method from system dynamics modelling - seem suited. This instrument tries to fully cover the potential benefits - including difficult recognizable effects - of IT investments by showing interdependencies between the single impacts. Influence diagrams facilitate the monetarization of impacts in the form of increasing revenues or cost savings [39]. Beyond process-centric impacts, the monetarization of effects is a crucial subject in order to face the requirements of IT executives, who are under increasing pressure to motivate the impact of IT investments regarding the quality, productivity and competiveness of the organization [34]. The major challenge is the transformation of qualitative 
effects into monetary values. Assistance is given through methods that bridge classical investment calculations and influence diagrams, e.g. the consideration of savings in working time. Following, the value items and suitable procedures to measure and monetize them are derived.

4.2.1. Items to measure $B P$ performance. As examined in the use cases, several latency types cause delays during the process flows. Real-time IT components may remove or reduce these latencies, e.g. through a faster data provision or higher data timeliness [29]. Based on the technical enhancements (direct effects) several benefits arise on BP level, especially through faster processing and decision cycles. Faster processing may lead to cost reductions and improved product quality. BP efficiency generally is determined by three target dimensions: process-time, -quality and -costs [37]. Discussing and simulating the reduction of the identified latencies in the use cases with real-time technologies, these three dimensions have been specified in the form of different value items.

Economy of working hours, primarily resulting from shorter response and faster data provisioning times, are one major process-related effect that, among others, induce a higher level of interactive processing and shorter decision cycles. The outcome of time savings are reduced personnel expenditures. An example for the 'associated management $\mathrm{BP}^{\mathrm{C}}$ is the reduction of manually efforts to collect timely data from different transactional systems as usual in (near) real-time environments in case of missing realtime IT infrastructures. Investigating quantitative measurement methods, 'activity based costing' seems appropriate to evaluate the benefits of reduced personnel expenditures. In contrast to traditional accounting, the calculation focuses on activities and processes that are affected by IT investments.

Faster provision of decision-critical information as well as the possibility to work on transactional mass data may positively affect the process quality. Reduced error rates are one indicator to determine this effects. If an error, occurring e.g. in the manufacturing process, becomes apparent earlier due to faster information flows, countermeasures to fix this fault can be implemented quicker. Consequently, the error concerns less produced vehicles. Lower reject rates in turn cause a lower amount of vehicles that need to be reworked. Hence, reduced error rates are translatable into cost savings. Quality expenditures consists of costs to improve process quality and costs to eliminate faults. Besides, utilization rates of resources and thus, organizational productivity may increase. High capacity utilization is particularly important for enterprises with a high proportion of fixed costs (energy supplier, OEMs).

Furthermore, responsiveness in BPs increases, if timely data is available. A faster reaction on changing business capacities or customer needs avoids costs of subsequent adjustments and reinforces the competitive position [20]. As a result of enhanced organizational flexibility, communication and coordination and thus, planning and decision-making in the associated management BPs are improved [4]. Moreover, companies strive to improve decision quality. Timely access to decision-relevant information is seen as a driver to change user behavior and as enabler to realize new BPs and business models. Fig. 2 comprises all indicated value items that are arising with regard to the transactional and associated management BP level.

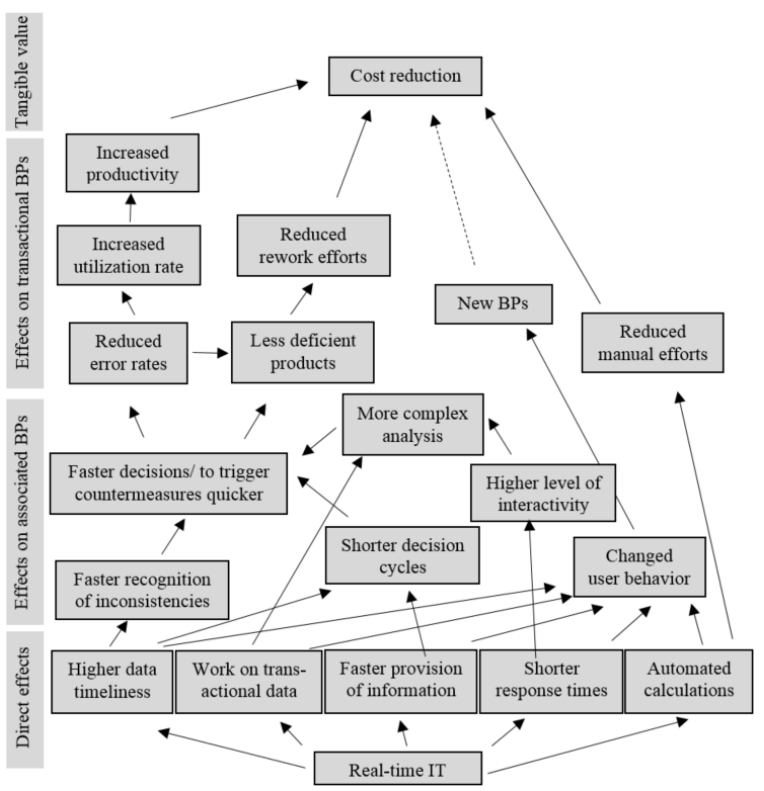

Figure 2. Real-time IT value items

As illustrated already in a few prior case studies, recently especially discussing the value of IMDM, analytical BPs also benefit from real-time IT infrastructures. Initial IMDM implementations emphasized the enhancement of data analyses in analytical applications. Hence, real-time components support, for example, interactive analyses on transactional real-time data, the realization of Big Data environments and an integrated view on structured and unstructured data as well as interactive planning runs or simulations [40].

4.2.2. Items to measure user satisfaction. For the purpose to investigate the provision of real-time information, system response times (SRT) and the 
level of interactive processing are essential aspects to consider with regard to the user respectively the decision-maker. Faster response times should lead to a higher level of user interactivity (amongst others). Interactivity denotes the range to which users are able to modify the form and content of a system in realtime [41]. Fundamental recommendations for typical SRTs have remained constant over the last 50 years. [42] intensively examined correlations between SRTs and the user productivity as well as user satisfaction. the use of different parameters that judge the employee behavior (e.g. status of employee's illness, accident rate [44]). Due to a better practicability, the model only considers 'staff turnover' and 'status of employee's illness'. Higher rates of staff turnover cause increased costs, e.g. for staff recruitment, and costs for decreased output. A challenge arises from determining the proportion of resignations and days of illness that actually results from dissatisfaction and emotional stress, due to an insufficient IT-support.

Table 3. Internal business value creation

\begin{tabular}{|c|c|c|}
\hline $\begin{array}{l}\text { Internal Value } \\
\text { dimension }\end{array}$ & Value item & Measurement procedures \\
\hline \multirow{3}{*}{$\begin{array}{l}\text { Associated } \\
\text { management } \\
\text { process } \\
\text { effectiveness }\end{array}$} & Level of interactivity & to measure system response times (automated or manually) in seconds \\
\hline & $\begin{array}{l}\text { Decision cycle } \\
\text { (frequency, speed) }\end{array}$ & $\begin{array}{l}\text { to measure latencies in data and information flow (in minutes or } \\
\text { hours) }\end{array}$ \\
\hline & Flexibility & Models to measure decision-making flexibility and process flexibility \\
\hline \multirow{4}{*}{$\begin{array}{l}\text { Transactional } \\
\text { process } \\
\text { effectiveness }\end{array}$} & Personnel expenditure & Activity based costing \\
\hline & Process quality & $\begin{array}{l}\text { To assess error rates by the use of the parameters: error prevention } \\
\text { costs, costs for error detection, defective products, warranties, error } \\
\text { removal }\end{array}$ \\
\hline & Productivity & $\begin{array}{l}\text { Ratio between output and input quantity, index 'utilization rate', } \\
\text { index 'rework' (in minutes per day), index adherence to schedules } \\
\text { and delivery dates }\end{array}$ \\
\hline & $\begin{array}{l}\text { New business models } \\
\text { and processes (soft fact) }\end{array}$ & - \\
\hline \multirow[t]{2}{*}{$\begin{array}{l}\text { Satisfaction } \\
\text { decision-maker }\end{array}$} & $\begin{array}{l}\text { employees' attitude } \\
\text { towards the company }\end{array}$ & $\begin{array}{l}\text { employee survey and interview, index 'staff turnover', 'status of } \\
\text { employee's illness' }\end{array}$ \\
\hline & Employee productivity & Index 'labor productivity' \\
\hline
\end{tabular}

Derived from an analysis of a vast number of studies and laboratory experiments, the author demonstrates significant performance impairments (error count, number of transactions) in case of long SRTs as well as decreasing user satisfaction and a negative impact on productivity. Keeping the user's attention focused on a transaction or task is limited on ten seconds, although after one second the feeling to operate directly on the data is already lost [43]. SRTs that exceed the indicated values prevent interactive analyses, planning runs or simulations [32]. If a user expects to interactively work on real-time data, long SRTs will cause discontent. As observed in the cases too, technical restrictions reinforce negative user perceptions, if an employee's target agreements are linked to its productivity or the department performance is judged on the basis of indicators as processing times, first passes, rework minutes or error rates. The result of dissatisfied employees are lower work performance, complaints, absenteeism, or even resignations. It is assumed that right-time provision of relevant timely information and the improved decision-support are leading to increased user satisfaction and a reduced loss of human capital. Hence, the employees' attitude towards the company and their productivity are further value items.

For evaluating the employees' attitude, direct methods as interviews, surveys or workshops are applicable. Further, the satisfaction is investigable by
All indicated value items have been compressed to main items. Tab. 3 gives a summary including reasonable measurement methods. Following, an overview of initial validation results is given.

\subsection{Validation}

The above described theoretical model and measurement approach is currently being used and validated in a series of exploratory case studies. This paper exemplarily reports on two operational BP scenarios (already mentioned at the beginning) that have been identified as BPs with (near) real-time information requirements: (i) quality audit and (ii) internal material supply of the production line. As described in the methodology section, the identification of these scenarios has been supported by the use of special assessment indicators (cited in section 4.1.). For the two BPs, the internal organizational benefits of real-time IT infrastructures have been determined with the aid of the value items and measurement procedures purposed before (Tab. 3). More precisely, the impacts of real-time information at the points of decision and action in each BP have been derived in workshops together with the BP's operational area managers, discussing the single value items defined before (Tab. 3). Later, the impacts have been monetarized as far as possible using the measurement procedures recommended. 
For simulating the cost reductions, data from 2015 has been analyzed, for example the impact on error rates and personnel expenditures, if an action is implemented $x$ hours/minutes earlier.

In the quality audit (i) one day passes until occurring errors have been reported. Until now, 95\% of the daily manufactured vehicles, which have been produced later than the defective one, have already left the plant at the time of error detection and reporting. In scenario (ii) time-intensive error analysis on various transactional IT systems are necessary in case of disruptions and missing parts at the production line. Missing parts imply a rejection and rework of vehicles and thus, additional costs. Hence, a pro-active control of critical situations is required to prevent outages.

As indicated by the results, implementing a realtime solution involves benefits for both the transactional BP and the associated management BP. But, subject to the setting, the intensity fluctuates. Substantial improvements in (i) particularly result from changes of internal communication processes linked with supporting real-time IT components (digital failure recording, alerting functions). Hence, detected errors are reported and removed up to 17 working hours earlier than before. Consequently, significant savings of rework and warranty costs arise. Taking the number of items per hour into account, one error may affect about 900 vehicles less.

By contrast, benefits for scenario (ii) especially arise on the transactional BP level. By using a realtime system, disturbances in material flows are proactively recognized. Further, the transactional BP is supplemented with two new real-time technologysupported functions that positively impact the delivery reliability in case of emergencies. Increased utilization rates of tugger trains as well as reduced resource and personnel expenditures are ensuing.

\section{Table 4. Exemplary benefits from real-time IT}

\begin{tabular}{|c|c|c|c|}
\hline Dimension & Value item & BP Quality audit & BP Material supply \\
\hline \multirow{2}{*}{$\begin{array}{l}\text { Associated } \\
\text { management } \\
\text { BP } \\
\text { effectiveness }\end{array}$} & Level of interactivity & Irrelevant for the scenario & Few seconds \\
\hline & Decision cycle & $\begin{array}{l}\text { Errors are reported and } \\
\text { countermeasures are } \\
\text { implemented up to } 17 \mathrm{~h} \\
\text { earlier }\end{array}$ & $\begin{array}{l}\text { Interruption detection } \\
\text { cycle reduced from } 10 \mathrm{~min} \\
\text { to } 0 \min \text {-real-time } \\
\text { decision }\end{array}$ \\
\hline \multirow{4}{*}{$\begin{array}{l}\text { Transactional } \\
\text { BP } \\
\text { effectiveness }\end{array}$} & $\begin{array}{l}\text { Personnel } \\
\text { expenditure }\end{array}$ & $\begin{array}{l}\text { Reduced rework efforts: } \\
30 \% \text { (anonymized data) }\end{array}$ & $\begin{array}{l}\text { Reduced rework efforts: } \\
20.000 \text { \$ }\end{array}$ \\
\hline & Process quality & $\begin{array}{l}75 \% \text { less faulty vehicles } \\
\text { after error detection } \\
\text { Warranty costs: - } 50 \% \\
\text { (anonymized data) }\end{array}$ & $\begin{array}{l}99 \% \text { less missing items } \\
\text { and line stoppages - } \\
\text { saving: } 40.000 \$\end{array}$ \\
\hline & Productivity & $\begin{array}{l}\text { Irrelevant for the } \\
\text { scenario }\end{array}$ & $\begin{array}{l}\text { Utilization rate of tugger } \\
\text { trains increases from } 75 \% \\
\text { to } 90 \%: \text { minus } 105.000 \$\end{array}$ \\
\hline & $\begin{array}{l}\text { New business models } \\
\text { and processes (soft } \\
\text { fact) }\end{array}$ & $\begin{array}{l}\text { Redesign of } \\
\text { communication } \\
\text { processes - promptly } \\
\text { report of errors and } \\
\text { measures to production } \\
\text { line } \\
\text { Digital failure recording }\end{array}$ & $\begin{array}{l}\text { New functions in } \\
\text { transactional BP to ensure } \\
\text { delivery reliability in case } \\
\text { of emergency } \\
\text { Real-time IT triggers real- } \\
\text { time reaction due to full } \\
\text { transparency }\end{array}$ \\
\hline $\begin{array}{l}\text { Satisfaction } \\
\text { decision- } \\
\text { maker }\end{array}$ & $\begin{array}{l}\text { Employees' attitude } \\
\text { towards the company } \\
\text { and productivity }\end{array}$ & $\begin{array}{l}\text { Increased user } \\
\text { satisfaction confirmed; } \\
\text { detailed results are not } \\
\text { yet available }\end{array}$ & $\begin{array}{l}\text { Increased user satisfaction } \\
\text { confirmed - detailed } \\
\text { results are not yet available }\end{array}$ \\
\hline
\end{tabular}

According to the model described above, the value effects have been structured and calculated (Tab. 4). As the examples illustrate, the impacts fluctuate across the different BP levels according to the scenario. The business value in (i) is primarily caused by an adjustment of the associated management BPs that consequently lead to significant monetary effects on the transactional BP level. In contrast, transactional BPs in (ii) directly benefit from real-time IT to a greater extend. But, monetary values always arise from effects on transactional BP level.

Beside the emphasized internal value, effects on firm performance have been discussed briefly in the cases. For example, less defective vehicles and consequent warranties are supposed to have a positive impact on customer satisfaction and the company's competitive position. Higher customer satisfaction may cause revenue growths. Constructing respective influence diagrams, which assist in translating the impacts in the form of increasing revenues, is a field for future research.

Each scenario that has been identified as suitable for a (near) real-time information support should be evaluated as described above. Possibly, not all value items are appropriate for single BPs. By summarizing all single monetary benefits from each affected BP total savings are calculable. These benefits have to be compared to the expenditures for new IT components (licenses, training, maintenance etc.) and internal changes in order to decide on an IT investment.

In the case studies, any results for the dimension 'employee satisfaction' haven't received so far. It is planned to conduct an employee satisfaction survey, employing a conjoint analysis. By using this method, it is intended to identify the problems that bother (process-related) employees most. Afterwards, the percentage of IT-related dissatisfaction may be transferred to the mentioned performance indicators.

\section{Conclusions}

This research contributes by advancing the understanding of the benefits of real time analytics and decision making. With the advent of real-time technologies for practical application, companies are faced with the question whether and which investments in real-time capabilities are reasonable. The paper helps to overcome lacking economic analyses of real-time technologies by purposing an adapted process-oriented business value model inclosing a measurement approach that helps assessing and quantifying internal organizational implications. In particular, it presents relevant value items and measurement procedures to monetize the 
internal benefit of a real-time information environment. Thus, prior process-oriented approaches have been expanded by the aspects of monetarization. Beyond investigating how to measure the business value, the model initially considers, if real-time technologies are reasonable for an organization. Further, the paper presents initial validation results of the measurement approach.

Operationalized on the example of real-time IT infrastructures it has been proven that purely implementation of IT infrastructures does not directly generate business value. Moreover, the cases indicate varying impacts for different BP types. Accordingly, the value items have been structured distinguishing three BP types. For illustrating the multi-level impacts, influence diagrams are suited that have been connected to the BP context. The validation examples illustrate the reduction of communication costs as a result of implementing IT systems that realize (near) real-time information and decision-cycles. Thus, efficiency and effectiveness of transactional BPs may improve. The indirect occurrence of monetary effects on the transactional BP layer has been documented. Additional, a positive relationship between enhancements on the layer of associated management BPs and transactional BPs has been exposed.

The concept helps to assess the impact of realtime technologies economically, which is essential in order to calculate business cases. Further, the model might assist organizations to transform to stronger real-time driven value chains. These are also a condition for realizing digital supply chains. Provided that every involved company internally uses the concept purposed, the value of real-time technologies for intercorporate end-to-end BPs might be measurable similar. Examining, if the identified value items are adaptable to this context, is a field for future investigations.

The applicability of the model to other industries that are confronted with similar challenges is supposed. Although initial results have only been applied to manufacturing companies, the model including the measurement approach takes a generic practice and is believed to be applicable to other industries (in process: Tab.1, case D, E) and process (e.g. strategic management BPs). Future studies may address respective validations, too. Furthermore, structuring competitive effects (Fig. 1 [d]) of realtime IT infrastructures, e.g. the impact on customer satisfaction, is a future research field. This strongly refers to examining how revenue growths are supported through real-time technologies.

\section{References}

[1] Lee, I., J.Y.-T. Leung, and S.H. Son, Handbook of Real-Time and Embedded Systems, Chapman \& Hall, Boca Raton and Fla, 2008.

[2] Vom Brocke, J., S. Debortoli, O. Müller, and N. Reuter, "How In-memory Technology Can Create Business Value: Insights from the Hilti Case", Communications of the A, Vol. 34, 2014, pp. 151-168.

[3] Bärenfänger, R., B. Otto, and H. Österle, "Business value of in-memory technology - multiple-case study insights", Industrial Management \& Data Systems, 114(9), 2014, pp. 1396-1414.

[4] Tallon, P.P., "A Process-Oriented Perspective on the Alignment of Information Technology and Business Strategy", Journal of Management Information Systems, 24(3), 2007, pp. 227-268.

[5] Vom Brocke, J., A. Simons, B. Niehaves, K. Riemer, R. Plattfaut, and A. Cleven, "Reconstructing the Giant: On the Importance of Rigour in Documenting the Literature Search Process", in ECIS 2009 Proceedings, Paper 161.

[6] Yin, R.K., Case study research: Design and methods, 4th edn., Sage Publications, Thousand Oaks, Calif, 2009.

[7] Chari, M.D.R., S. Devaraj, and P. David, "Research Note - The Impact of Information Technology Investments and Diversification Strategies on Firm Performance", Management science, 54(1), 2008, pp. 224-234.

[8] Hitt, L. and E. Brynjolfsson, "The three faces of IT value: theory and evidence", ICIS 1994 Proceedings, p. 20.

[9] Bharadwaj, A.S., "A Resource-Based Perspective on Information Technology Capability and Firm Performance: An Empirical Investigation", MIS Quarterly, 24(1), 2000, p. 169.

[10] Barua, A., C.H. Kriebel, and T. Mukhopadhyay, "Information Technologies and Business Value: An Analytic and Empirical Investigation", Information Systems Research, 6(1), 1995, pp. 3-23.

[11] Kohli, R. and V. Grover, "Business Value of IT: An Essay on Expanding Research Directions to Keep up with the Times", Journal of the AIS, 9(2), 2008, pp. 23-39.

[12] Beath, C., D. Goodhue, R. MacGregor, P.-A. Nielsen, and J. and Turner, "Partnering for Business Value: The Shared Management of the IS Infrastructure", in ICIS 1994 Proceedings, Vancouver, Paper 50.

[13] Mooney, J.G., V. Gurbaxani, and K.L. Kraemer, "A Process Oriented Framework for Assessing the Business Value of Information Technology", SIGMIS Database, 27(2), 1996, pp. 68-81.

[14] Tallon, P.P., K.L. Kraemer, and V. Gurbaxani, "Executives' Perceptions of the Business Value of Information Technology: A Process-Oriented Approach", Journal of MIS, 16(4), 2000, pp. 145-173. 
[15] Srinivasan, A., "Alternative Measures of System Effectiveness: Associations and Implications", MIS Quarterly, 9(3), 1985, pp. 243-253.

[16] DeLone, W.H. and E.R. McLean, "Information Systems Success: The Quest for the Dependent Variable", Information Systems Research, 3(1), 1992, pp. 60-95.

[17] Davis, F.D., "Perceived usefulness, perceived ease of use, and user acceptance of information technology", MIS Quarterly, 13(3), 1989, pp. 318-346.

[18] Melville, N., K. Kraemer, and V. Gurbaxani, "Review: Information Technology and Organizational Performance: An Integrative Model of IT Business Value", MIS Quarterly, 28(2), 2004, pp. 283-322.

[19] Shang, S. and P.B. Seddon, "Assessing and managing the benefits of enterprise systems: The business manager's perspective", Information Systems Journal, 12(4), 2002, pp. 271-299.

[20] Davenport, T. and J. Snabe, "How fast and flexible do you want your information, really?", MIT Sloan Management Review, Vol. 52(No. 3), 2011, pp. 57-62.

[21] Marjanovic, O., "Business Value Creation through Business Processes Management and Operational Business Intelligence Integration", in Proceedings of the 43rd Hawaii International Conference on Systems Science, HI. 2010.

[22] Eckerson, W.W., "Best practices in operational BI: Converging Analytical and Operational Processes", TDWI Best practices report, 2007.

[23] Koch, M.T., H. Baars, H. Lasi, and H.-G. and Kemper, "Manufacturing Execution Systems and Business Intelligence for Production Environments", in AMCIS 2010 Proceedings, Lima, Peru, Paper 436.

[24] Hänel, T. and C. Felden, "Operational Business Intelligence Meets Manufacturing", in Proceedings of the 19th Americas Conference on Information Systems. 2013.

[25] Polites, G.L., "From Real-Time BI to the Real-Time Enterprise: Organizational Enablers of Latency Reduction", in Proceedings of ICIS 2006, Milwaukee.

[26] Marjanovic, O., "The Next Stage of Operational Business Intelligence: Creating New Challenges for Business Process Management", in Proceedings of the 40th Hawaii International Conference, Waikoloa, HI. 2007.

[27] Korotina, A., O. Mueller, and S. Debortoli, "Real-time Business Process Intelligence. Comparison of different architectural approaches using the example of the order-tocash process.", in Wirtschaftsinformatik Proceedings 2015, pp. 1710-1724.

[28] Berg, B. and P. Silvia, SAP HANA: An introduction, 2nd edn., 2012.

[29] Plattner, H. and A. Zeier, In-memory data management: An inflection point for enterprise applications, Springer, Berlin, 2011.

[30] Acker, O., F. Gröne, A. Blockus, and C. Bange, "Inmemory analytics - strategies for real-time CRM", Journal of Database Marketing \& Customer Strategy Management Management), 18(2), 2011, pp. 129-136.

[31] Lehner, W. and G. Piller, eds., IMDM 2011 Proc Innovative Unternehmensanwendungen mit In-Memory, 2011.

[32] Piller, G. and J. Hagedorn, "Business benefits and application capabilities enabled by in-memory data management", in IMDM 2011 Proceedings Innovative Unternehmensanwendungen mit In-Memory, W. Lehner and G. Piller, Editors. 2011.

[33] Wessel, P., Köffer, S., Becker, J., "Auswirkungen von In-Memory-Datenmanagement auf Geschäftsprozesse im Business Intelligence", in Wirtschaftsinformatik Proceedings 2013, Leipzig, pp. 1781-1795.

[34] Schryen, G., "Revisiting IS business value research: what we already know, what we still need to know, and how we can get there", European Journal of Information Systems, 22(2), 2013, pp. 139-169.

[35] DeLone, W.H. and E.R. McLean, "The DeLone and McLean Model of Information Systems Success: A TenYear Update", J. Manage. Inf. Syst., 19(4), 2003, pp. 9-30.

[36] Cundius, C. and Alt, R., " Real-time or near real-time? - Towards an real-time assessment model", in ICIS 2013 Proceedings, Milano.

[37] Davenport, T.H., "Process Innovation-Reengineering work through Information Technology", Harvard Business School Press, Boston, 1993, p. 5.

[38] Davenport, T.H., "Business intelligence and organizational decisions", Organizational Applications of Business Intelligence Management: Emerging Trends: Emerging Trends, 2012, p. 1.

[39] Pidd, M., Computer simulation in management science, 5th edn., Wiley, Chichester, England, Hoboken, NJ, 2004.

[40] Loos, P., J. Lechtenbörger, G. Vossen, A. Zeier, J. Krüger, J. Müller, W. Lehner, D. Kossmann, B. Fabian, O. Günther, and R. Winter, "In-memory Databases in Business Information Systems", Business \& Information Systems Engineering, 3(6), 2011, pp. 389-395.

[41] Shen, C.-C. and H.-M. Chuang, "An Investigation on User Communication Behavior in an Interactive Whiteboard Technology Environment", WTOC, 8(1), 2009, pp. 184-195.

[42] Hollig, H., Psychische Beanspruchung durch Wartezeiten in der Mensch-Computer Interaktion, Springer Berlin Heidelberg, 1989.

[43] Nielsen, J., Usability engineering, Morgan Kaufmann Publishers, San Francisco, Calif, 1994.

[44] Krause, H.-U. and D. Arora, Key performance indicators: bi-lingual compendium German/English, Oldenbourg, München, 2008. 